\section{Questions for the palaeoecologist}

\section{Peter D. Moore}

Past and Present Vegetation of the Far

Northwest of Canada.

By J.C. Ritchie.

University of Toronto Press: 1984.

Pp.251. \$35, £29.75.

THE most remote corner of Canada, the far Northwest, may seem an unlikely setting for a book about vegetational history. But, as Jim Ritchie points out in his introduction, there are several very good reasons why it should be regarded as a source of interest. In the first place there is its glacial history; rather surprisingly much of the area has escaped major glaciation, certainly for the past half-million years, so we might well expect long, undisturbed profiles of stratified sediments to have accumulated there. Then there is the fact that the region forms the eastern edge of Beringia - the last terrestrial point of contact between the Old World and the New across what are now the Bering Straits. Add to this the wide range of climatic regimes and vegetation types, and the Northwest can be seen to be full of promise for the palaeoecologist.

Ritchie begins by setting the physical and biological scene for the palaeovegetation studies. His emphasis is upon the contrasting environments of the Northwest which result from the gradient between the continental-subarctic climate with early springs in the south, and the arctic-coastal climate with late springs in the north. But the data presented here are not always easy to appreciate simply because there is no map of the locations named. Lack of a map also makes it difficult to interpret some of the intriguing periglacial geomorphology of the region. Take pingos, for example. How does their distribution relate to the limits of glaciation? Are they located only on unglaciated terrain?

A very helpful map of the major vegetation zones is supplied covering not only the Northwest, but also Alaska and eastern Siberia, and is supplemented by outline descriptions of the vegetation types of the area. Detailed lists and phytosociological analyses are given in appendices.

But the main part of the book is given over to the history of vegetation and reconstruction of palaeoenvironments, starting from Tertiary times but concentrating upon the Quaternary. Much of the Tertiary data, which must by now be available as a result of oil exploration, is still hidden from the public gaze and scientific scrutiny.

In view of the unglaciated nature of much of the Northwest terrain, one might hope for long cores of sediment recording Quaternary vegetation history; sadly, this is not the case. Ancient sediments, perhaps dating back about 700,000 years, have been found in river-bank exposures but no continuous core has yet been obtained.

The last 13,000 years are very well documented from many sites, largely as a result of Ritchie's own work, and the results not only provide a picture of the changing vegetation of the Northwest, but also illustrate many of the problems currently facing palaeoecologists. How do we interpret pollen assemblages for which there is apparently no modern analogue? What are the relative merits and limitations of percentage and influx diagrams? What interpretive allowances must be made for the size of sampling site?

The mass of data and the wealth of

problems described are finally pulled together in a general reconstruction of environmental history. This particular approach results in the combined advantages of a full and detailed picture of the changing vegetation of this interesting area, together with the salutary lessons to be gained from the practical problems encountered in the process. The latter point will make the book valuable even to palaeoecologists whose research interests are far removed from the remote Northwest.

Peter D. Moore is Reader in Ecology in the Department of Plant Sciences, King's College, University of London.

\section{Fresh fusion}

\section{I.H. Hutchinson}

Introduction to Plasma Physics and

Controlled Fusion, 2nd Edn.

Vol. 1 Plasma Physics.

By Francis F. Chen.

Plenum: 1984. Pp. 421. \$24.50, £23.28.

Fusion: An Introduction to the Physics and Technology of Magnetic

Confinement Fusion.

By Weston M. Stacey, Jr.

Wiley: 1984. Pp. 260. \$39.95, £46.20.

WHEN an author publishes a second book covering a specialized scientific topic, as is the case for both books reviewed here, the immediate question that springs to mind is "why?". What is the relationship of the new book to his earlier one? In the case of Francis F. Chen's Introduction to Plasma Physics and Controlled Fusion the answer is straightforward: in this second edition of a work originally published in 1974, he plans an expansion of the fusion section into a complete volume, the plasma physics now also taking an entire book. We shall await the appearance of that second volume with interest; meanwhile the present book, apart from some corrections, valuable additions to the chapter on nonlinear effects, and a change to SI units, deviates very little from its predecessor. This is perfectly justifiable since Chen's book has become widely accepted as an excellent introductory text in plasma physics. Its emphasis on intuitive understanding and the copious sketches and diagrams help to make it truly accessible to undergraduates in both physics and engineering.

The author's objective of including where possible all algebraic steps in the development is achieved with surprisingly few tedious sections; however, sometimes this principle leads him to omit the derivation entirely when an outline would have been helpful. It is hard for the student to rectify this failing using other sources because the references are limited mostly to papers whose results are included in figures in the book. Such minor points apart, this is a deeply satisfying book, full of insight and with a very happy choice of material for a first course in plasma physics. The serious student will want to go further, but this is a good place to start.

The question "why" is more difficult to answer for Weston M. Stacey's Fusion. Neither the subtitle, An Introduction to the Physics and Technology of Magnetic Confinement Fusion, nor the preface are of much help. The first half of the book consists of an overview of the plasma physics of magnetic confinement. Most of this material, including 18 of the figures, is abstracted from Stacey's Fusion Plasma Analysis which appeared only three years ago. Whatever the merits of the earlier book, abbreviating the material for the present work has resulted in a distinctly light-weight treatment. Such an introduction is perhaps appropriate for a nonspecialist student; certainly the text is easy to read; but unfortunately it is hard to escape the feeling that simplification has led to superficiality.

The latter half of the book consists of an introduction to the engineering and technology involved in fusion reactor design. Of great merit here is the wealth of physical data included in the form of tables and graphs, which lend a valuable tone of solidity to the engineering issues. Sections on nuclear activation and tritium breeding and handling are particularly welcome. But again the brevity of the treatment and the frequent lack of a proper explanation of the quantities under discussion leaves the reader uncertain of the rigour of any conclusions.

For someone wanting to become broadly acquainted with the various aspects of fusion research, Stacey's book offers a readable introduction. But it is not one which lays a particularly firm technical foundation for detailed research in the field.

I.H. Hutchinson is an Associate Professor in the Department of Nuclear Engineering at the Massachusetts Institute of Technology.

- Also recently published by Wiley is Fusion Energy, by Robert A. Gross, a graduate-level introduction to the principles behind fusion science and technology. Price is $\$ 41.95, £ 42.90$. 